\title{
Superiority of Serum Immunofixation Electrophoresis over Serum Protein Electrophoresis in the Diagnosis of Multiple Myeloma
}

\author{
MM UDDIN $^{\mathrm{a}}$, MM RAHMAN $^{\mathrm{b}}$, SA SULTANA $^{\mathrm{c}}$, D SAHA $^{\mathrm{d}}$
}

\begin{abstract}
Summary:
Background: Multiple Myeloma (MM) is a neoplasm of B cell lineage characterized by excessive proliferation of abnormal plasma cells, secreting abnormal immunoglobulin causing monoclonal gammopathy which can be detected by the presence of M protein in serum and urine electrophoresis.

Aim: Present study is aimed to detect and quantify monoclonal gamma globulins by SPEP and IFE in suspected case of MM and other plasma cell dyscrasias and also to find out the discrepant findings between SPEP and IFE.

Methods: A retrospective observational study was carried out on clinically highly suspected cases of Multiple Myeloma (MM) presenting with backache, asthenia and generalized weakness at Armed forces Institute of Pathology(AFIP), Dhaka cantonment from January 2015 to July 2016. A total of 140 blood samples were collected and subjected to serum protein electrophoresis (SPEP) and Immunofixation electrophoresis (IFE). IFE identifies the type of heavy (IgG, $\operatorname{IgM}$ or IgA) and light chain (either kappa or lambda in suspected cases of MM
\end{abstract}

Introduction:

The Multiple Myeloma (MM) is a progressive B cell haematological malignancy characterized by

a. Col Mohammed Mosleh Uddin, Classified Specialist in Pathology, Combined Military Hospital, Dhaka.

b. Col Md Mizanur Rahman, Classified Specialist in Pathology, Armed Forces Institute of Pathology, Dhaka Cantonment, Dhaka.

c. Dr Syeda Adib Sultana, Consultant, Department of Medicine, Delta Medical College, Mirpur, Dhaka

d. Major General Debashish Saha, Commandant, Armed Forces Institute of Pathology, Dhaka Cantonment, Dhaka.

Address of Correspondance: Col Mohammed Mosleh Uddin, Classified Specialist In Pathology, Combined Military Hospital, Dhaka. Mobile: +8801726774346; e-mail: moslehuddin746@yahoo.com

Received: 4 Oct. 2017

Accepted: 22 March 2018
Results: Out of 140 cases, SPEP identified monoclonal band in 62 cases and either non-specific findings or polyclonal band in 78 cases. At the same time immunofixation electrophoresis (IFE) which was done on all samples detected another 14 cases of M-band in addition to earlier 62 cases of monoclonal gammopathy by SPEP. Among 140 cases, SPEP detected M-band in 62 cases, whereas IFE identified monoclonal band in 76 cases. So in the remaining 14 cases (10\%) small sharp spikes of monoclonal band was found only by IFE whereas SPEP failed to detect those 14 cases.

Conclusion: SPEP is an easy to perform laboratory test which can be used for detection and quantification of monoclonal gammopathy but there is some limitation in detecting monoclonal band by SPEP. IFE is more sensitive to detect the monoclonal band than SPEP. So both SPEP and IFE should be done simultaneously for precise diagnosis of MM and related disorders.

Keywords: Multiple Myeloma, Bone marrow, Serum Protein Electrophoresis, Immunofixation electrophoresis.

(J Bangladesh Coll Phys Surg 2018; 36: 95-100) DOI: http://dx.doi.org/10.3329/jbcps.v36i3.37031

unregulated and clonal proliferation of plasma cells of the bone marrow (BM), which produce and secrete anomalous monoclonal immunoglobulin or fragments of those (free light chain or Bence Jones Protein), called M-protein, Myeloma protein or paraprotein, which are secreted into blood and /or urine ${ }^{1,2}$. In haematological neoplasm, MM is the disease with relatively bad prognosis and lower survival rates, 5 years in $15 \%-20 \%$ of cases $^{3}$.

International Center of Cancer registry have reported an increase in incidence rates and mortality caused by MM in recent decades although it is not yet clear whether this is due to the new means of diagnosis or an actual increase in new cases of the disease ${ }^{3}$. 
The presentation of MM can range from asymptomatic to severely symptomatic, which includes back pain,renal failure, pathologic fracture, recurrent infections, weakness and bleedingt .

The diagnosis of MM depends on identification of monoclonal plasma cells in the BM, M- protein in the serum and/ urine and evidence of lytic bone lesionsu . The use of efficient and accurate technique for diagnosis is essential to differentiate other forms monoclonal gammopathyv. Currently, Serum Protein Electrophoresis (SPEP) remains the standard technique for the diagnosis of patients with $\mathrm{MMw}$. Although capillary protein electrophoresisis considered a relatively simple laboratory method for the detection of M- protein, but Serum Immunofixation Electrophoresis (IFE) technique is now considered a gold standard for confirming the presence of these protein and to distinguish light and heavy chain in MMx . Present study is aimed to detect and quantify monoclonal gamma globulins by SPEP in suspected case of $\mathrm{MM}$ and other plasma cell dyscrasia and also to find out the discrepant findings between SPEP and IFE.

\section{Materials and Methods:}

This retrospective observational study was carried out at Armed Forces Institute of Pathology (AFIP), Dhaka Cantonment from January 2015 to July 2016. A total of 140 blood samples were collected from clinically suspected cases of MM and other plasma cell dyscrasia and subjected to SPEP and IFE in the department of haematology, AFIP. Protein electrophoresis of the samples was performed by automated capillary electrophoresis machine, Capiflex 2 which identifies the various protein bands and depicts as a graph. The $\mathrm{M}$ band is usually found in the gamma globulin region but in a few cases it is identified in the beta region also. The machine identifies the $\mathrm{M}$ protein both qualitatively and quantitatively.

Immuno fixation electrophoresis (IFE) was also performed by the same capillary electrophoresis machine Capiflex 2. IFE identifies the type of heavy (IgG, IgM or $\operatorname{IgA}$ ) and light chain (either kappa $[\kappa]$ or lambda $[\lambda$ ) in suspected cases of MM and other plasma cell dyscrasia.

\section{Results:}

A total of 140 clinically suspected cases of MM and other plasma cell dyscrasia were included in this study during the period from January 2015 to July 2016.
Initially, SPEP were performed on all samples. Sixty two cases were detected as monoclonal gammopathy and remaining 78 cases showed either non-specific findings or polyclonal gammopathy. Among 62 cases, $46(74.2 \%)$ were male and $16(25.8 \%)$ were female. The male to female ratio was 2.9:1. Majority of the patients belonged to the age group of 61 to 70 years. Demographic data are shown in Table I. Table II shows the pattern of protein electrophoresis by capillary SPEP in 140 cases.

\section{Table-I}

Demographic data of Patient with monoclonal
Gammopathy $(n=62)$

\begin{tabular}{lccc} 
Age & Male & Female & Total \\
\hline $41-50$ & 08 & 02 & 10 \\
$51-60$ & 12 & 02 & 14 \\
$61-70$ & 18 & 08 & 26 \\
$71-80$ & 04 & 02 & 06 \\
$81-90$ & 02 & 02 & 04 \\
$91-100$ & 02 & - & 02 \\
\hline Total & 46 & 16 & 62 \\
\hline
\end{tabular}

Of monoclonal gammopathy cases (62), 46(74.2\%) cases had the M-band in the $\operatorname{gamma}(\gamma)$ region and $16(25.8 \%)$ cases in the beta-globulin ( $\beta)$ region on capillary SPEP. No M-band was found in the alpha $(\alpha)$ region. Table-III shows the distribution of monoclonal ("M") band on electrophoretic strip with their mean concentration.

All samples (140) were subjected to IFE irrespective of their electrophoretic pattern in SPEP. By IFE, monoclonal band was detected in 76 samples including all 62 cases of monoclonal gammopathy by SPEP. Another 14 cases from 78 cases (detected earlier as either non-specific findings or polyclonal gammopathy by SPEP) were also detected as monoclonal gammopathy by IFE. Therefore in 14 cases, capillary SPEP failed to identify monoclonal band. Protein electrophoretic pattern by IFE is shown in Table IV. Table V shows the discrepancy of monoclonal band between SPEP and IFE.

Among the total 76 cases of monoclonal gammopathy, distribution of heavy and light chain iso-type is shown in table VI. Out of 14 cases of monoclonal gammopathy detected by IFE but found non-specific findings on SPEP, 12 cases had IgG kappa and two cases IgG lambda which is shown in table VII. 


\section{Table-II}

Electrophoretic pattern of proteins on capillary SPEP $(n=140)$

\begin{tabular}{llcc} 
S/No & Type & No & $\%$ \\
\hline 01 & Monoclonal gammopathy & 62 & $44.2 \%$ \\
02 & Polyclonal gammopathy & 34 & $24.2 \%$ \\
03 & Acute inflammation (Raised \pm 2 globulin) & 06 & $4.2 \%$ \\
04 & Malignant tumors & 02 & $1.4 \%$ \\
05 & Non Specific Findings (NSF) & 32 & $23.0 \%$ \\
06 & Hypoalbuminemia & 04 & $3.0 \%$ \\
\hline
\end{tabular}

\section{Table-III}

Distribution of monoclonal (" $M$ ") band on electrophoretic strip with their mean concentration in SPEP $(n=62)$

\begin{tabular}{lccc}
$\begin{array}{l}\text { Beta globulin } \\
\text { region }\end{array}$ & $\begin{array}{c}\text { Mean protein } \\
\text { concentration }(\mathrm{gm} / \mathrm{dL})\end{array}$ & $\begin{array}{c}\text { Gamma } \\
\text { globulin region }\end{array}$ & $\begin{array}{c}\text { Mean protein } \\
\text { concentration }(\mathrm{gm} / \mathrm{dl})\end{array}$ \\
\hline $16(25.8 \%)$ & $4.60(2.8-6.8)$ & $46(74.2 \%)$ & $4.84(2.4-6.9)$ \\
\hline
\end{tabular}

\section{Table-IV}

\section{Distribution of pattern of Electrophoresis} in IFE $(n=140)$

\begin{tabular}{|c|c|c|c|c|c|}
\hline Electrophoretic pattern in IFE & Number & $\%$ & SPEP & IFE & Discrepancy \\
\hline Monoclonal band & 76 & 54 & $62(44 \%)$ & $76(54 \%)$ & $14(10 \%)$ \\
\hline
\end{tabular}

Table-V

\section{Discrepancy of monoclonal band between} SPEP and IFE $(n=140)$

Table-VI

Distribution of Heavy and Light chain iso-types $(n=76)$ of monoclonal band

\begin{tabular}{llcc} 
S/NO & Isotype of Heavy and Light chain & Number & $\%$ \\
\hline 1 & IgG Kappa Monoclonal gammopathy & 56 & $73.7 \%$ \\
2 & IgG Lambda Monoclonal gammopathy & 10 & $13.2 \%$ \\
3 & IgA Kappa Monoclonal gammopathy & 08 & $10.5 \%$ \\
4 & IgM Kappa Monoclonal gammopathy & 02 & $2.6 \%$ \\
\hline
\end{tabular}

\section{Table-VII}

Heavy and light chain iso-type of discrepant cases detected by IFE $(n=14)$

\begin{tabular}{lllcc} 
S/No & SPEP & IFE & Number & $\%$ \\
\hline 01 & NSF & IgG Kappa & 12 & $85.7 \%$ \\
02 & NSF & IgA Lambda & 2 & $14.3 \%$ \\
\hline
\end{tabular}




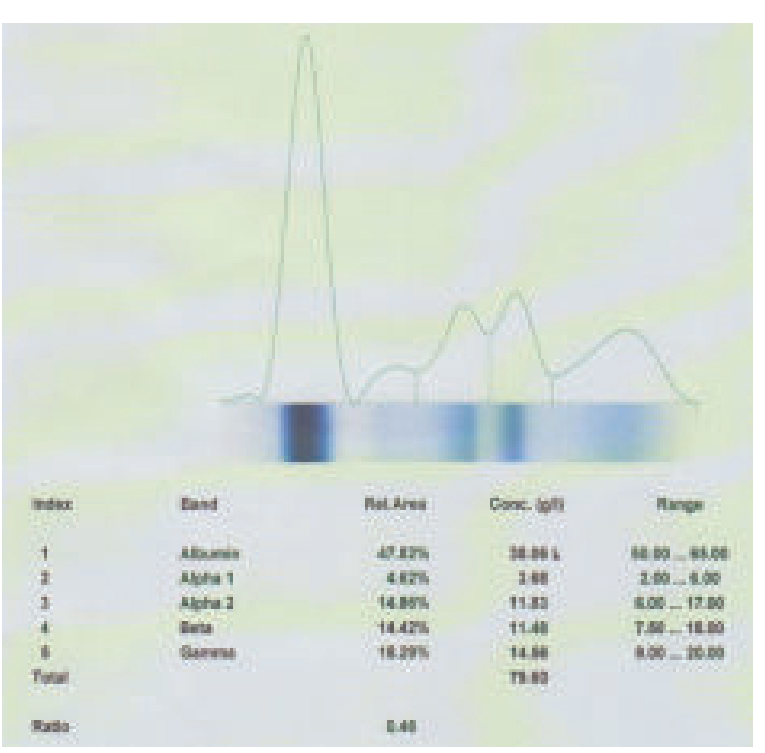

Fig.-1: Non specific findings.

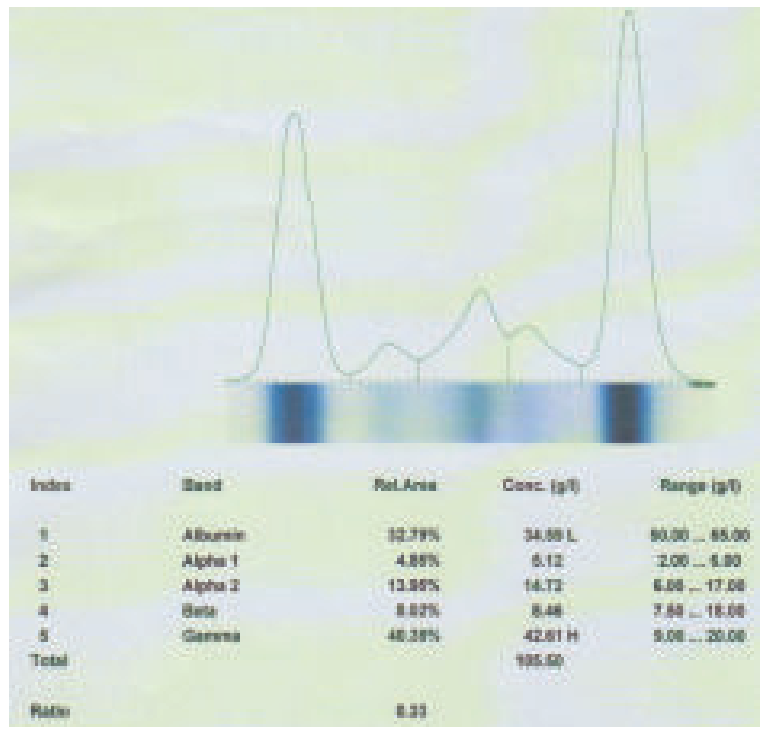

Fig.-II: SPEP showing monoclonal gammopathy

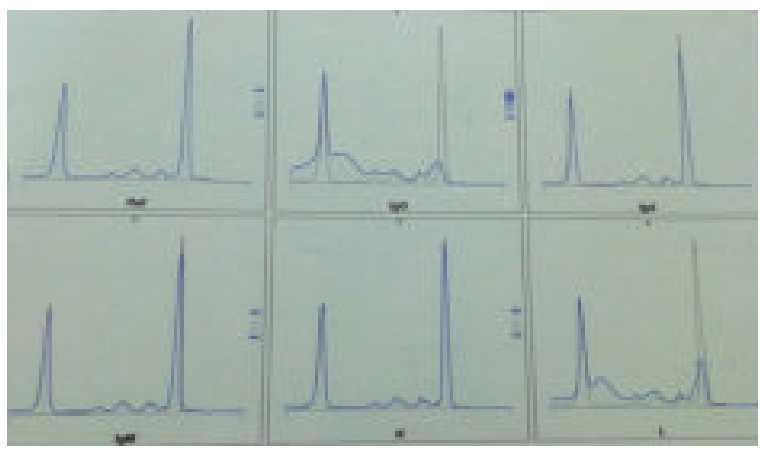

Fig.-III: IFE showing IgG Lambda monoclonal gammopathy.

\section{Discussion:}

Multiple Myeloma, a cancer of terminally differentiated plasma cells, typically occurs in elderly patients. The prevalence of this disease is about $1 \%$ of all the cancers but the incidence increases after the age of 60 yearsy. Normally the plasma cells constitute $1 \%$ of the cells in the bone marrow, but as the disease progresses, the tumor load in the bone marrow increases up to $80 \%$, depending upon the disease severity. These malignant plasma cells synthesize monoclonal antibodies which are released into the circulation. Therefore this monoclonal protein (antibody) level in the serum increases ${ }^{10}$.In the clinical practice, serum protein electrophoresis(SPEP) is commonly used to identify multiple myeloma and other serum protein disorder. Many specialists include SPEP as a screening test in the initial evaluation for numerous clinical conditions ${ }^{11}$. Serum Immunofixation Electrophoresis (IFE) is more sensitive laboratory test than SPEP, which is used for early detection of multiple myeloma.

In this study, out of 140 suspected cases of multiple myeloma, $44.3 \%$ (62 cases) were found to have monoclonal gammopathy, whereas Chopra at al, found $24.4 \%$ sample positive for the M-protein by SPEP ${ }^{12}$, Giti Set al reported 6.3\% samples $^{13}$ and Delwar at al reported 9.2\% samples had monoclonal gammopathy in their studies ${ }^{1} t$, Tripathy Sreported 16 cases (10.7\%) of multiple myeloma in her study ${ }^{1} u$. The high percentage of getting monoclonal gammopathy in this study may be explained by taking samples that are highly suspected clinically to have MM as well as small sample size. Low percentage of finding monoclonal band in Giti et al' study was probably due to random selection of samples and large sample size (442).

The analysis of medical records of 62 patients with confirmed diagnosis of MM in our study indicated that the mean age was 63 years, ranging from 61-70 years. This finding correlates most of the published articles ${ }^{13}$, ${ }^{14,15,}{ }^{1} \mathrm{~V}$.

Among $62 \mathrm{M}$ band positive cases, M- spike was observed in the gamma region in $46(74.2 \%)$ cases and 16 cases $(25.8 \%)$ had it in beta region. This finding is similar to the study carried out by Giti S et al ${ }^{13}$, but differs from Chopra's study where $84.8 \%$ of the cases had the $\mathrm{M}$ band in gamma region and $15.2 \%$ cases in beta globulin region ${ }^{12}$. This slight difference may be 
due to the inclusion of large number of case in Chopra's study.

The 62 cases of MM in this study indicated predominance of IgG Kappa monoclonal gammopathy (73.7\%),followed by IgG lambda (13.2\%), IgA kappa (10.5\%) and IgM kappa monoclonal gammopathy $(2.6 \%)$, and Giti $\mathrm{S}$ et al ${ }^{13}$ also reported IgG kappa monoclonal protein in $80 \%$ of cases and $\mathrm{IgG}$ lambda monoclonal protein in $20 \%$ of cases which is almost similar to our study. The results of the present study also correlates with the study of Bouatary et al where most common myeloma was IgG Kappa followed by IgG Lambda monoclonal gammopathy ${ }^{1} \mathrm{~W}{ }^{~}{ }^{1} \mathrm{X}$.

Serum IFE method is considered the Gold standard ${ }^{19}$, ${ }^{20}$ with high sensitivity and specificity to detect a small monoclonal protein early and to distinguish the heavy chains from light chains present in the serum and urine of patient with MM. In our study, monoclonal band was detected in 76 cases by serum IFE technique, whereas SPEP method could detect 62 cases only. So in the remaining 14 cases $(10 \%)$, a small sharp spike of monoclonal band was found by IFE method whereas SPEP technique could not detect those cases. Among the 14 small spikes detected by IFE method, 12 cases were IgG Kappa and 2 cases were IgA Lambda monoclonal gammopathy.

The greater sensitivity of serum IFE in relation to SPEP in detecting monoclonal immunoglobulin, found in this study, correlates with several studies conducted mainly in $2015^{21}$ and $1990^{22}$. But working with a group of 101 samples, Poldevin et al $(1983)^{23}$ found that they were correctly identified as monoclonal band in 50 cases by gel SPEP, in comparison with 97 M-band by IFE. This low sensitivity of SPEP is due to the inability of that technique (gel SPEP) to detect low concentration of monoclonal immunoglobulin $(<1 \mathrm{gm} /$ Liter) ${ }^{2} \mathrm{t}$.

\section{Conclusion:}

The present study showed that there is some limitation in detecting monoclonal band by SPEP. IFE is more sensitive to detect the monoclonal band than SPEP, therefore for diagnosing $\mathrm{MM}$ and related disorders, both SPEP and IFE or only IFE should be done to have a definitive result.

\section{Conflict of interest:}

No conflict of interest.

\section{References:}

1. Barber FD. Multiple myeloma; early recognition by primary care nurse practitioners. J nurse Pract 2006; 2(10):665-72

2. PaszekovaH, KrykovF,KubiczkobaL,HaJekR,Sevcikova S. High risk multiple myeloma: different definition, different outcome? Clin lymphoma myeloma leuk 2014; 14(1):24-30

3. AltieriA, CheriB, Bermejo J, Castro F, Haemminkia K. Familial risks and temporal incidence trends of multiple myeloma. Eur J cancer 2006 ;42:1661-70.

4. The international Myeloma working group. The criteria for the classification of the monoclonal gammopathies, multiple myeloma and the related disorder. Br J Haematol 2003; 121:749-57.

5. Kyle RA, Rajkumar IV. Criteria for Diagnosis, staging, risk stratification and response assessment of multiple myeloma. Leukemia 2009; 23:3-9.

6. San Miguel JF, GutierrezNC,Maleo G, Orfao A. Conventional diagnosis in multiple myeloma. Eur J cancer 2006; 42:1510-19.

7. San Miguel JF ,Paiva B, Gutierrez NC. New tools for diagnosis and monitoring of multiple myeloma. Am SocclinoncolEduc Book.2013;313-8.

8. Rajkumar SV .Multiple myeloma. Curr probl cancer 2009; 33(1): 7-64.

9. Adnan AZ, David HV. Multiple myeloma: An Old diseases with a new hope for the future.CA Cancer J clin 2001:51:273-85.

10. Mehta KD, Khambu B, Lakhey M, Baral N, Majhi S. The diagnosis of multiple myeloma by the demonstration of the $\mathrm{M}$ protein in the bone marrow aspirate, by agar gel electrophoresis: A case report . Kathmandu University Medical Journal 2006;4(4): 513-16.

11. O' Connell TX, Horiba TJ,Kasravi B. Understanding and interpreting serum protein electrophoresis .Am Fam Physician 2005 ;1(1):105-12.

12. Chopra GS, Gupta PK, Mishra DK.The evaluation of suspected monoclonal gammopathies: the experience in a tertiary care Hospital .MJAFI 2006; 62:134-37.

13. Giti S, RahmanMM, Islam MS, Saad AMH, Naznin L. The role of serum protein electrophoresis in the detection of multiple myeloma . Bangladesh Armed Forces Medical Journal. 2012;2(1):37-41.

14. Dilawar M,Liaz A,HafeezA,Akbar N,Khan FA, et al .The pattern of serum protein electrophoresis in various disease.Pak J Pathol 2005;16(1):22-27.

15. SunitaTripathy. The role of serum protein electrophoresis in the detection of multiple myeloma: An Experience of a Corporate Hospital . J clinDiagn Res 2012 Novenber; 6(9):1456-1461.

16. Fassan A, Tricot G. Results of high -dose treatment with autologous stem cell support in patients with multiple myeloma.SeminHaematol 2001;38:231-42. 
17. Boutay A, HIzen S, Youssef BY, et al. Multiple myeloma:Clinical ,Biologic and diagnostic aspects. Journal of immunology and biology 2013;28(1):30-5.

18. Faria RMD, Silva ROP. Monoclonal gammopathy- Criteria, diagnosis and differential diagnosis. Rev Bras HaematolHaemoter 2007; 29(1): 17-22.

19. Bender LM, Collan SW, Fedoring, Willis MS, Mccudden CR. Evaluation of digital image for identification and characterization of monoclonal immunoglobulins by immunofixation. ClinBiochaem 2013, 46:255-8.

20. HungriaVTM,Crusoe EQ, Quero M, Sampalo M, Maiolino A, Bernada WM. Guidelincs on the diagnosis and management of multiple myeloma. Rev res HaematolHaemoter 2013; 35(3): 201-17.
21. Martha HC, Luiz CA, Bruno C, Edson PS. Comparison between immunofixation and electrophoresis for the early detection of relapsed multiple myeloma. J Bras Patol, Med Lab 2015 December;51(6):359-68.

22. Karen DF. The use of high-resolution electrophoresis Kappa and lambda quantification and immunofixation to diagnose monoclonal gammopathies in serum. ClinImmunol 1990;7(1): 106-10.

23. Potdevin F, Roncalo M, Drupt F, Paris M, Leclerc M. Contribution of immunofixation on agarose gel in the characterisation of serum monoclonal immunoglobulins. Ann Institute Pasteur Immunol 1993;134(13): 105-23.

24. Vrelthaem M, Laussen B, Von Schenck H, Ernerudh J. Immunofixation to plasma agarose electrophoresis in detecting small M-components in patients with Polyneuropathy. J Neurol Sci 1993;120: 93-8. 